Prepared for the U.S. Department of Energy

under Contract DE-AC05-76RL01830

\title{
Assessment of Tidal Energy Removal Impacts on Physical Systems: Development of MHK Module and Analysis of Effects on Hydrodynamics
}

Fiscal Year 2011 Progress Report

Environmental Effects of Marine and Hydrokinetic Energy

Z Yang
T Wang

September 2011

Pacific Northwest

NATIONAL LABORATORY

Proudly Operated by Battelle Since 1965 


\title{
DISCLAIMER
}

This report was prepared as an account of work sponsored by an agency of the United States Government. Neither the United States Government nor any agency thereof, nor Battelle Memorial Institute, nor any of their employees, makes any warranty, express or implied, or assumes any legal liability or responsibility for the accuracy, completeness, or usefulness of any information, apparatus, product, or process disclosed, or represents that its use would not infringe privately owned rights. Reference herein to any specific commercial product, process, or service by trade name, trademark, manufacturer, or otherwise does not necessarily constitute or imply its endorsement, recommendation, or favoring by the United States Government or any agency thereof, or Battelle Memorial Institute. The views and opinions of authors expressed herein do not necessarily state or reflect those of the United States Government or any agency thereof.

\author{
PACIFIC NORTHWEST NATIONAL LABORATORY \\ operated by \\ BATTELLE \\ for the \\ UNITED STATES DEPARTMENT OF ENERGY \\ under Contract DE-AC05-76RL01830
}

Printed in the United States of America
Available to DOE and DOE contractors from the
Office of Scientific and Technical Information,
P.O. Box 62, Oak Ridge, TN 37831-0062;
ph: (865) 576-8401
fax: $(865) 576-5728$
email: reports@adonis.osti.gov

\begin{abstract}
Available to the public from the National Technical Information Service,
U.S. Department of Commerce, 5285 Port Royal Rd., Springfield, VA 22161

ph: (800) 553-6847$$
\text { fax: }(703) 605-6900
$$

email: orders@ntis.fedworld.gov

online ordering: http://www.ntis.gov/ordering.htm
\end{abstract}

This document was printed on recycled paper. 


\section{Assessment of Energy Removal Impacts on Physical Systems: Development of MHK Module and Analysis of Effects on Hydrodynamics}

\section{Fiscal Year 2011 Progress Report}

Environmental Effects of Marine and Hydrokinetic Energy

Z Yang

T Wang

September 2011

Prepared for

the U.S. Department of Energy

under Contract DE-AC05-76RL01830

Pacific Northwest National Laboratory

Richland, Washington 99352 



\begin{abstract}
In this report we describe 1) the development, test, and validation of the marine hydrokinetic energy scheme in a three-dimensional coastal ocean model (FVCOM); and 2) the sensitivity analysis of effects of marine hydrokinetic energy configurations on power extraction and volume flux in a coastal bay.

Submittal of this report completes the work on Task 2.1.2, Effects of Physical Systems, Subtask 2.1.2.1, Hydrodynamics and Subtask 2.1.2.3, Screening Analysis, for fiscal year 2011 of the Environmental Effects of Marine and Hydrokinetic Energy project.
\end{abstract}





\section{Project Overview}

Energy generated from the world's oceans and rivers offers the potential to make substantial contributions to the domestic and global renewable energy supply. The U.S. Department of Energy (DOE) Office of Energy Efficiency and Renewable Energy (EERE) Wind and Water Power Program supports the emerging marine and hydrokinetic (MHK) energy industry. As partners in an emerging industry, MHK project developers face challenges with siting, permitting, construction, and operation of pilot- and commercial-scale facilities, as well as the need to develop robust technologies, secure financing, and gain public acceptance.

In many cases, little is known about the potential effects of MHK energy generation on the aquatic environment from a small number of devices or a large-scale commercial array. Nor do we understand potential effects that may occur after years or decades of operation. This lack of knowledge affects the solvency of the industry, the actions of regulatory agencies, the opinions and concerns of stakeholder groups, and the commitment of energy project developers and investors.

To unravel and address the complexity of environmental issues associated with MHK energy, Pacific Northwest National Laboratory (PNNL) is developing a program of research and development that draws on the knowledge of the industry, regulators, and stakeholders and builds on investments made by the EERE Wind and Water Power Program. The PNNL program of research and development - together with complementary efforts of other national laboratories, national marine renewable energy centers, universities, and industry - supports DOE's market acceleration activities through focused research and development on environmental effects and siting issues. Research areas addressed include

- categorizing and evaluating effects of stressors - Information on the environmental risks from MHK devices, including data obtained from in situ testing and laboratory experiments (see other tasks below) will be compiled in a knowledge management system known as Tethys to facilitate the creation, annotation, and exchange of information on environmental effects of MHK technologies. Tethys will support the Environmental Risk Evaluation System (ERES) that can be used by developers, regulators, and other stakeholders to assess relative risks associated with MHK technologies, site characteristics, waterbody characteristics, and receptors (i.e., habitat, marine mammals, and fish). Development of Tethys and the ERES will require focused input from various stakeholders to ensure accuracy and alignment with other needs.

- effects on physical systems - Computational numerical modeling will be used to understand the effects of energy removal on water bodies from the short- and long-term operation of MHK devices and arrays. Initially, PNNL's three-dimensional coastal circulation and transport model of Puget Sound will be adapted to test and optimize simulated tidal technologies that resemble those currently in proposal, laboratory trial, or pilot study test stages. This task includes assessing changes to the physical environment (currents, waves, sediments, and water quality) and the potential effects of these changes on the aquatic food webs) resulting from operation of MHK devices at both pilot- and commercial-scale in river and ocean settings.

- effects on aquatic organisms - Testing protocols and laboratory exposure experiments will be developed and implemented to evaluate the potential for adverse effects from operation of MHK devices in the aquatic environment. Initial studies will focus on electromagnetic field effects, noise associated with construction and operation of MHK devices, and assessment of the potential risk of 
physical interaction of aquatic organisms with devices. A variety of fish species and invertebrates will be used as test animals, chosen due to their proximity to and potential susceptibility to MHK devices.

- permitting and planning - Structured stakeholder communication and outreach activities will provide critical information to the project team to support execution of other project tasks. Input from MHK technology and project developers, regulators and natural resource management agencies, environmental groups, and other stakeholder groups will be used to develop the user interface of Tethys, populate the database, define the risk attributes of the ERES, and communicate results of numerical modeling and laboratory studies of exposure of test animals to MHK stressors. This task will also include activities to promote consideration of renewable ocean energy in national and local Coastal and Marine Spatial Planning activities.

The team for the Environmental Effects of MHK Energy development project is made up of staff, faculty, and students from

- Pacific Northwest National Laboratory

- Marine Sciences Laboratory (Sequim and Seattle, Washington)

- Risk and Decision Sciences (Richland, Washington)

- Knowledge Systems (Richland, Washington)

- Oak Ridge National Laboratory (Oak Ridge, Tennessee)

- Sandia National Laboratories (Albuquerque, New Mexico; Carlsbad, California)

- Oregon State University, Northwest National Marine Renewable Energy Center (Newport, Oregon)

- University of Washington, Northwest National Marine Renewable Energy Center (Seattle, Washington)

- Pacific Energy Ventures (Portland, Oregon).

- University of Massachusetts - Dartmouth

- WorleyParsons Westmar Corp. 


\title{
Acronyms and Abbreviations
}

\author{
1-D one-dimensional \\ 2-D two-dimensional \\ 3-D three-dimensional \\ DOE U.S. Department of Energy \\ EERE DOE Office of Energy Efficiency and Renewable Energy \\ ERES Environmental Risk Evaluation System \\ FVCOM Finite Volume Coastal Ocean Model \\ MHK marine and hydrokinetic \\ PNNL Pacific Northwest National Laboratory
}





\section{Contents}

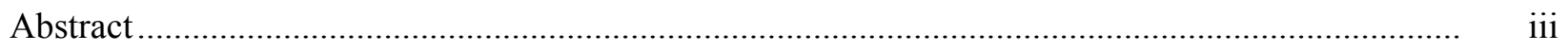

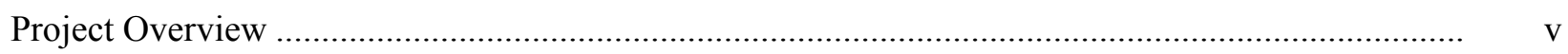

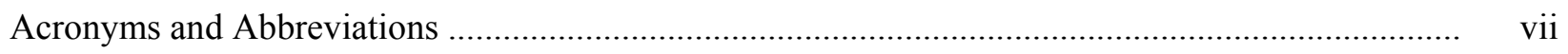

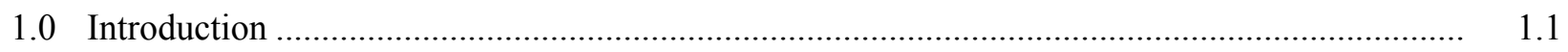

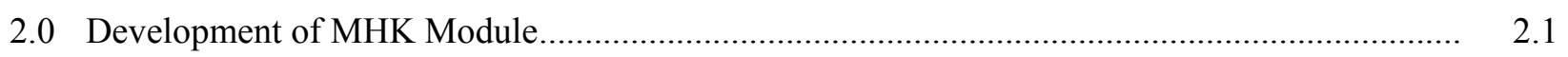

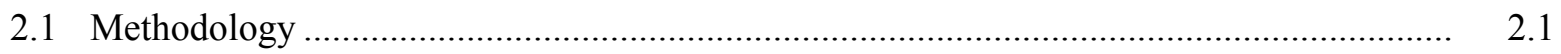

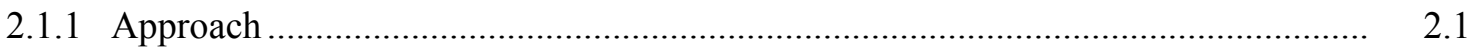

2.1.2 Implementation of MHK Scheme in a Coastal Ocean Model ................................ 2.1

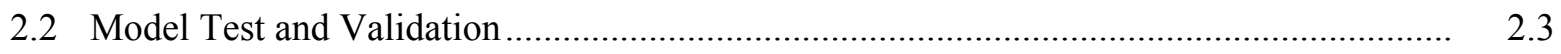

2.2.1 Numerical Model........................................................................................... 2.3

2.2.2 Model Setup in a Semi-Enclosed Tidal Bay ..................................................... 2.3

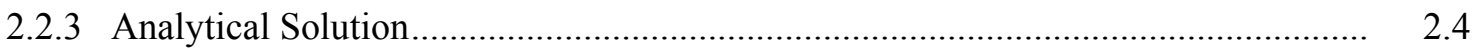

2.2.4 Power Extraction with Momentum Sink Approach ........................................... 2.5

2.2.5 Power Extraction with Bottom Friction Approach............................................. 2.6

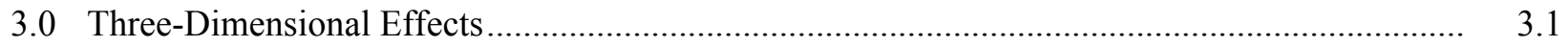

3.1 Three-Dimensional Effect on Velocity Profile …........................................................ 3.1

3.2 3-D Effect on Maximum Extractable Energy and Volume Flux...................................... 3.2

4.0 Screening Analysis of MHK Array Configurations ........................................................... 4.1

5.0 MHK Effects on Hydrodynamics and Flushing Time ........................................................ 5.1

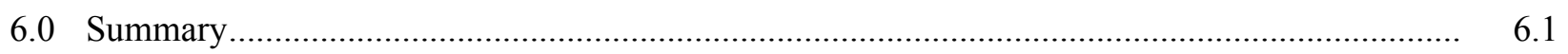

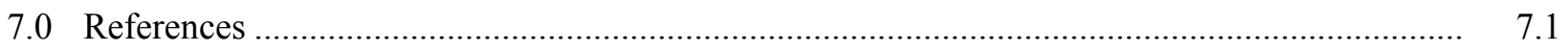

\section{Figures}

2.1 Model Domain and Elements with Tidal Turbines .............................................................. 2.4

2.2 Extractable Power as a Function of Volume Flux ............................................................... 2.5

2.3 Extractable Power and Volume Flux Ratio vs. Number of Tidal Turbines in

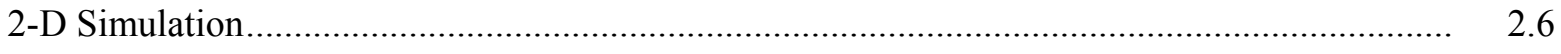

2.4 Extractable Power and Volume Flux Ratio vs. Bottom Friction in 2-D Simulations .................. 2.7

3.1 Vertical Velocity Profiles at Peak Flood at the Center of the Tidal Channel for Different Numbers of Tidal Turbines ................................................................................. 3.1

3.2 Effect of Turbine Height on Vertical Velocity Profiles .......................................................... 3.2

3.3 Extractable Power and Volume Flux Ratio vs. Number of Tidal Turbines in

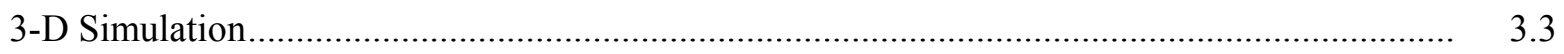

4.1 Grid Distribution Around the Tidal Turbines and Simulated Velocity Distribution .................. 4.1

4.2 Turbine Array Configurations in the Channel .................................................................... 4.2 
5.1 Simulated Tidal Amplitude Distributions Without and With 10 Tidal Turbines per Cell.

5.2 Simulated Surface Tidal Currents at Flood and Ebb Tides Without and With

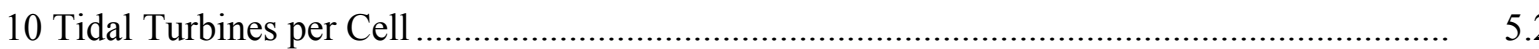

5.3 Simulated Tracer Concentrations Without and With Tidal Turbines at $20^{\text {th }}$ day after Initial Release

5.4 Effect of the Number of Turbines on the Flushing Time 5.4

5.5 Flushing Time Increment vs. Flow Reduction 5.4

\section{Tables}

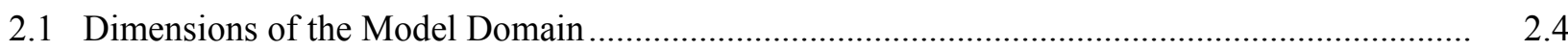

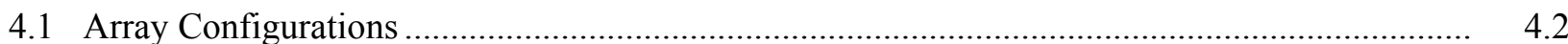




\subsection{Introduction}

There has been increasing interest in extraction of tidal energy from the ocean as a carbon-free renewable energy source, in response to the growing concerns over global climate change. One advantage of tidal energy is its high predictability in comparison to other sources of renewable energy. Traditional tidal energy extraction is based on a tidal barrage approach in which power is generated by the head difference during ebb and flood tides. However, there are many environmental concerns from the tidal barrage approach due to the isolation of the embayment, extreme water level changes of water impounded behind the barrage, and the reduction of tidal current speeds in the bay (Parker 1993; Pelc and Fujita 2002).

In recent years, more attention has been given to in-stream tidal hydrokinetic energy technology, in which tidal energy is extracted from strong tidal currents, in a similar way to wind power. Compared with the traditional tidal barrage approach, in-stream tidal energy extraction is relatively new and generally considered more cost-effective and less environmentally destructive (Polagye et al. 2011). There have been few studies on in-stream tidal hydrokinetic energy extraction in coastal regions.

An increasing number of analytical and numerical modeling studies have been conducted recently to evaluate the amount of extractable power from a tidal system and the potential associated environmental impact on the system. Garrett and Cummins $(2005,2007)$ examined the available tidal power potential in a one-dimensional (1-D) tidal channel with analytical models. Atwater and Lawrence (2010) and Polagye and Malte (2011) subsequently extended a similar 1-D modeling approach to tidal systems with a split tidal channel and even more complex channel networks, respectively. There are also a small number of studies on tidal power extraction using two-dimensional (2-D) numerical models by incorporating the tidal turbine feature into the models for assessment of tidal energy extraction (Sutherland et al. 2007; Sun et al. 2008; Walkington and Burrows 2009; Draper et al. 2009). Most recently, three-dimensional (3-D) models have been applied to study tidal energy extraction in field sites (e.g., Shapiro 2010). Because tidal flows are generally 3-D in nature, a 3-D approach will provide the most realistic assessment of extractable power and allow for assessment of the associated impacts on water circulation and the environment.

This report summarizes the implementation of marine and hydrokinetic (MHK) devices in the model, model validation with an analytical solution, and sensitivity analysis on MHK array configuration and the difference between 2-D and 3-D modeling approaches. 



\subsection{Development of MHK Module}

\subsection{Methodology}

\subsubsection{Approach}

There are two common approaches to simulate the effect of tidal hydrokinetic energy extraction using numerical models. The first is the bottom friction approach in which the tidal energy dissipation associated with the presence of tidal turbine is approximated by increasing bottom friction (Atwater and Lawrence 2010; Garrett and Cummings 2005; Sutherland et al. 2007). This approach is commonly used in analytical analysis and depth-averaged 2-D numerical model simulations and is easy to be implemented with a hydrodynamic model and will be introduced briefly in this report. The second approach is the momentum source/sink approach in which a volumetric momentum sink term is added to the momentum equations representing the loss of momentum due to tidal energy extraction by the hydrokinetic devices in a system as well as friction and form drag by the physical structures of the devices. This study focuses on the momentum sink approach that is described in detail in this section.

The volumetric momentum extraction rate for hydrokinetic devices can be defined in a general form as follows:

$$
\overrightarrow{F^{M}}=-\frac{1}{2} C_{e} A|\vec{u}| \vec{u}
$$

where $\quad \overrightarrow{F^{M}}=$ the volumetric momentum extraction rate from a waterbody by hydrokinetic devices $\left(\mathrm{m}^{4} / \mathrm{s}^{2}\right)$

$C_{e}=$ the momentum extraction coefficient

$A=$ the flow-facing area of devices $\left(\mathrm{m}^{2}\right)$

$\vec{u}=$ the velocity vector $(\mathrm{m} / \mathrm{s})$.

The total momentum removal rate by a tidal turbine can be divided into three parts that correspond to energy dissipated by 1) turbine blades, 2) device supporting poles, and 3) the device foundation, in a similar form to Equation (2.1):

$$
\overrightarrow{F^{M}}=-\frac{1}{2}\left[\left(C_{T}+C_{b}\right) A_{b}+C_{p} A_{p}+C_{f} A_{f}\right]|\vec{u}| \vec{u}
$$

where $\quad C_{T}=$ the turbine thrust coefficient due to momentum removal for power generation

$$
\begin{aligned}
C_{b}, C_{p}, \text { and } C_{f}= & \text { the drag coefficients due to physical structure of turbine blades, supporting } \\
& \text { poles and the foundation } \\
A_{b}= & \text { the total flow-facing area swept by turbine blades } \\
A_{p} \text { and } A_{f}= & \text { the total flow-facing areas of the supporting pole and device foundation }\left(\mathrm{m}^{2}\right), \\
& \text { respectively. }
\end{aligned}
$$

\subsubsection{Implementation of MHK Scheme in a Coastal Ocean Model}

To implement MHK devices into a 3-D hydrodynamic model such as the Finite Volume Coastal Ocean Model (FVCOM), the original governing equations need to be modified to include the MHK 
device effect. Specifically, the momentum equations for the horizontal velocities need to be updated to include the additional momentum sink terms representing the MHK device effects (Equation 2.2)).

The modified horizontal momentum governing equations are

$$
\begin{aligned}
& \frac{\partial u}{\partial t}+u \frac{\partial u}{\partial x}+v \frac{\partial u}{\partial y}+w \frac{\partial u}{\partial z}-f v=-\frac{1}{\rho_{o}} \frac{\partial p}{\partial x}+\frac{\partial}{\partial z}\left(K_{m} \frac{\partial u}{\partial z}\right)+F_{x}-F_{x}^{M} \\
& \frac{\partial v}{\partial t}+u \frac{\partial v}{\partial x}+v \frac{\partial v}{\partial y}+w \frac{\partial v}{\partial z}+f u=-\frac{1}{\rho_{o}} \frac{\partial p}{\partial y}+\frac{\partial}{\partial z}\left(K_{m} \frac{\partial v}{\partial z}\right)+F_{y}-F_{y}^{M}
\end{aligned}
$$

where $(x, y, z)=$ the east, north, and vertical axes in the Cartesian coordinates

$(u, v, w)=$ the three velocity components in the $x, y$, and $z$ directions

$\left(F_{u}, F_{v}\right)=$ the horizontal momentum diffusivity terms in the $x$ and $y$ directions

$K_{m}=$ the vertical eddy viscosity coefficient

$\rho=$ density

$p=$ pressure

$f=$ the Coriolis parameter.

Inserting Equation (2.2) into Equations (2.3) and (2.4) yields

$$
\begin{aligned}
& \frac{\partial u}{\partial t}+u \frac{\partial u}{\partial x}+v \frac{\partial u}{\partial y}+w \frac{\partial u}{\partial z}-f v+\left[\left(C_{T}+C_{b}\right) A_{b}+C_{p} A_{p}+C_{f} A_{f}\right]|\vec{u}| u \\
& =-\frac{1}{\rho_{o}} \frac{\partial p}{\partial x}+\frac{\partial}{\partial z}\left(K_{m} \frac{\partial u}{\partial z}\right)+F_{x} \\
& \frac{\partial v}{\partial t}+u \frac{\partial v}{\partial x}+v \frac{\partial v}{\partial y}+w \frac{\partial v}{\partial z}+f u+\left[\left(C_{T}+C_{b}\right) A_{b}+C_{p} A_{p}+C_{f} A_{f}\right]|\vec{u}| v \\
& =-\frac{1}{\rho_{o}} \frac{\partial p}{\partial y}+\frac{\partial}{\partial z}\left(K_{m} \frac{\partial v}{\partial z}\right)+F_{y}
\end{aligned}
$$

Comparing Equations (2.5) and (2.6) to Equations (2.3) and (2.4), we can see that momentum sink terms corresponding to the hydrokinetic energy extraction can be solved in a similarly way to the Coriolis force term. FVCOM solves the governing equations using the finite-volume method and $\sigma$-coordinate transformation in the vertical direction. Assuming the tidal turbine blades occupy only one single $\sigma$-layer and are also located within one triangular grid cell (however, the supporting poles are allowed to occupy multiple layers), the integrated form of Equations (2.5) and (2.6) for the 3-D internal mode become

$$
\begin{gathered}
\frac{\partial\left(A_{e} \Delta_{\sigma} D u\right)}{\partial t}+R_{u}-f A_{e} \Delta_{\sigma} D v= \\
-\left[\frac{1}{2} N_{b}\left(C_{T}+C_{b}\right) A_{b}\left(u^{2}+v^{2}\right)^{\frac{1}{2}} u+\frac{1}{2} N_{p} C_{p} A_{p}\left(u^{2}+v^{2}\right)^{\frac{1}{2}} u+\frac{1}{2} N_{f} C_{f} A_{f}\left(u^{2}+v^{2}\right)^{\frac{1}{2}} u\right] \\
\frac{\partial\left(A_{e} \Delta_{\sigma} D v\right)}{\partial t}+R_{v}+f A_{e} \Delta_{\sigma} D u= \\
-\left[\frac{1}{2} N_{b}\left(C_{T}+C_{b}\right) A_{b}\left(u^{2}+v^{2}\right)^{\frac{1}{2}} v+\frac{1}{2} N_{p} C_{p} A_{p}\left(u^{2}+v^{2}\right)^{\frac{1}{2}} v+\frac{1}{2} N_{f} C_{f} A_{f}\left(u^{2}+v^{2}\right)^{\frac{1}{2}} v\right]
\end{gathered}
$$


where

$$
\begin{aligned}
A_{e}= & \text { triangular element surface area }\left(\mathrm{m}^{2}\right) \\
\Delta_{\sigma} D= & \sigma \text {-layer height }(\mathrm{m}) \\
R_{u} \text { and } R_{v}= & \text { all the rest momentum terms (including advection, diffusion, and } \\
& \text { pressure gradient terms as described in FVCOM Manual (Chen } \\
& \text { et al. 2006)) } \\
f A_{e} \Delta_{\sigma} D v \text { and } f A_{e} \Delta_{\sigma} D u= & \text { the Coriolis force terms in } \mathrm{x} \text { and y directions, respectively }\left(\mathrm{m}^{4} / \mathrm{s}^{2}\right) .
\end{aligned}
$$

The right-hand sides of Equations (2.7) and (2.8) are the sum of the momentum sink terms contributed by turbine blades, supporting poles, and foundations defined in Equation (2.2). $N_{b}, N_{p}$, and $N_{f}$ are numbers of turbines, turbine supporting poles, and foundations located in the $\sigma$ layer of the element.

Correspondingly, the integrated form for the 2-D external mode becomes

$$
\begin{gathered}
\frac{\partial\left(A_{e} D \bar{u}\right)}{\partial t}+R_{\bar{u}}-f A_{e} D \bar{v}= \\
-\sum_{\sigma=1}^{\sigma=k}\left[\frac{1}{2} N_{b}\left(C_{T}+C_{b}\right) A_{b}\left(u^{2}+v^{2}\right)^{\frac{1}{2}} u+\frac{1}{2} N_{p} C_{p} A_{p}\left(u^{2}+v^{2}\right)^{\frac{1}{2}} u+\frac{1}{2} N_{f} C_{f} A_{f}\left(u^{2}+v^{2}\right)^{\frac{1}{2}} u\right] \\
\frac{\partial\left(A_{e} D \bar{v}\right)}{\partial t}+R_{\bar{v}}+f A_{e} D \bar{u}= \\
-\sum_{\sigma=1}^{\sigma=k}\left[\frac{1}{2} N_{b}\left(C_{T}+C_{b}\right) A_{b}\left(u^{2}+v^{2}\right)^{\frac{1}{2}} v+\frac{1}{2} N_{p} C_{p} A_{p}\left(u^{2}+v^{2}\right)^{\frac{1}{2}} v+\frac{1}{2} N_{f} C_{f} A_{f}\left(u^{2}+v^{2}\right)^{\frac{1}{2}} v\right]
\end{gathered}
$$

where $\bar{u}$ and $\bar{v}$ are the vertically integrated velocity in $\mathrm{x}$ and $\mathrm{y}$ directions, respectively.

\subsection{Model Test and Validation}

\subsubsection{Numerical Model}

The numerical model used in this study is the FVCOM developed by Chen et al (2003). FVCOM is a 3-D unstructured-grid coastal ocean model that simulates water surface elevation, velocity, temperature, salinity, sediment, and water-quality constituents. The unstructured grid and finite volume approach employed in the model provides the geometric flexibility, and computational efficiency is well suited to simulate the effect of tidal turbines on a flow field at a fine scale in a large domain. FVCOM uses unstructured triangular cells in the horizontal plane and a sigma-stretched coordinate system in the vertical direction to better represent the complex horizontal geometry and bottom topography of an estuary. FVCOM has been applied to simulate tidal dynamics and circulations in many estuarine and coastal waters (Zheng et al. 2003; Zhao et al. 2006; Weisberg and Zheng 2006; Hu et al. 2008; Huang et al. 2008; Chen et al. 2009; Yang and Khangaonkar 2010; Lai et al. 2010; Yang et al. 2011; Xing et al. 2011).

\subsubsection{Model Setup in a Semi-Enclosed Tidal Bay}

Model validation is conducted in an idealized case in which a semi-enclosed bay is connected to the coastal ocean through a narrow tidal channel. The dimensions of the model domain are specified, similar to some real coastal tidal inlets with strong tidal currents. The dimensions are provided in Table 2.1. 
Table 2.1. Dimensions of the Model Domain

\begin{tabular}{cccccccc}
\hline \multicolumn{3}{c}{ Tidal Channel $(\mathrm{m})$} & \multicolumn{2}{c}{ Semi-Enclosed Bay $(\mathrm{m})$} & \multicolumn{2}{c}{ Open Boundary $(\mathrm{m})$} \\
\hline Length & Width & Depth & Length & Width & Depth & Depth & Tidal Range \\
\hline 30,000 & 6,000 & 60 & 150,000 & 30,000 & 100 & 200 & 2 \\
\hline
\end{tabular}

To investigate the effects of MHK devices in a tidal dominant system, river discharge and meteorological forcing are not considered in this study. The model is forced with the semi-diurnal tide (M2) only. One-meter tidal amplitude is specified uniformly along the open boundary. The model is run in the barotropic mode such that temperature and salinity are not simulated. The model domain consists of 258,703 triangular cells and 130,273 nodes. The bathymetry of the model domain is shown in Figure 2.1. The grid cells marked in red (a total of 1,140 cells as shown in Figure 2.1) in the narrow channel represent the grid cells for tidal turbine installation.

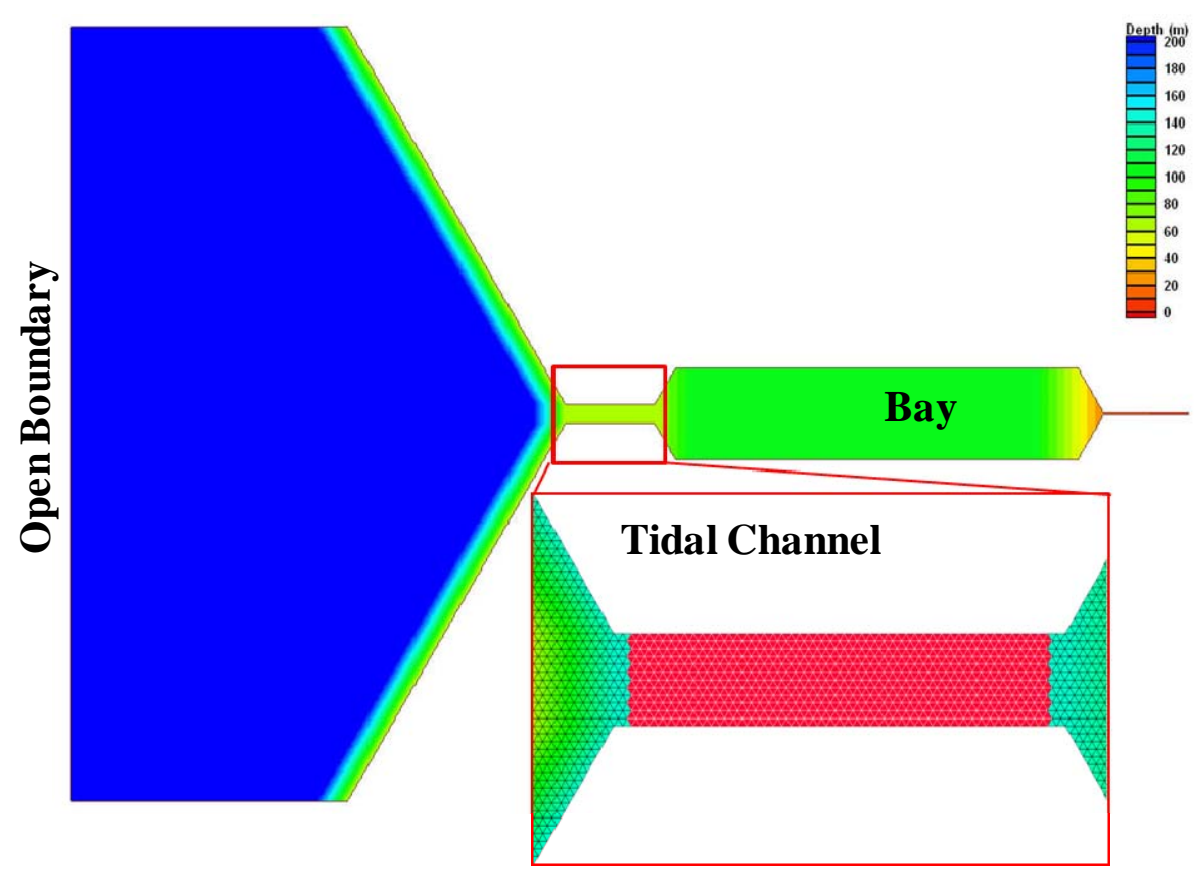

Figure 2.1. Model Domain and Grid Cells with Tidal Turbines (red)

\subsubsection{Analytical Solution}

An analytical solution was developed by Garrett and Cummins (2005) to calculate the power potential in tidal channels. The power potential $P$ can be related to the volume flux across the tidal channel in the following form:

$$
\frac{P}{P_{M A X}}=\left(\frac{3^{3 / 2}}{2}\right)\left(\frac{Q}{Q_{\operatorname{Max}}}\right)\left[1-\left(\frac{Q}{Q_{\operatorname{Max}}}\right)^{2}\right]
$$

where

$$
P_{M A X}=\gamma \rho g a Q_{M A X}=\text { the maximum power }
$$




$$
\begin{aligned}
Q_{\max }= & \text { the maximum volume flux in the natural tidal channel without the } \\
& \text { presence of hydrokinetic devices } \\
\rho & =\text { density } \\
a & =\text { the amplitude of the tidal height difference between the ends of channel } \\
g & =\text { the gravity acceleration } \\
\gamma & =\text { a coefficient varying from } 0.20 \text { to } 0.24 .
\end{aligned}
$$

$P$ reaches its maximum value $P_{\max }$ when $Q$ equals to $0.577 Q_{\max }$, or when $Q$ drops down to $57.7 \%$ of the natural volume flux (Figure 2.2).

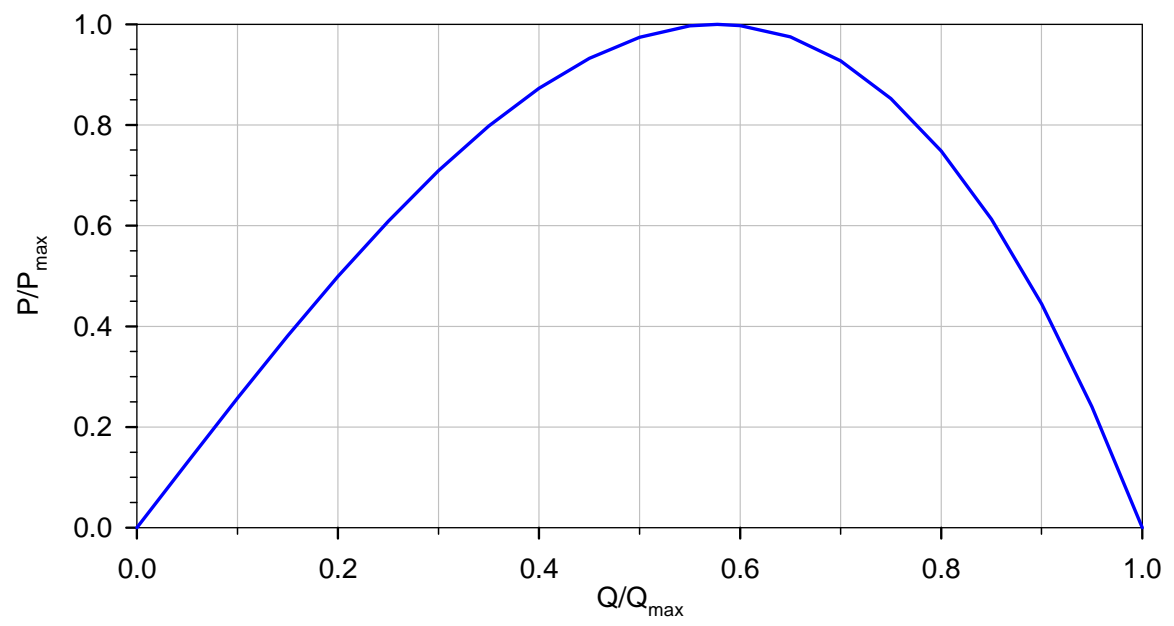

Figure 2.2. Extractable Power as a Function of Volume Flux. The Maximum Power Extraction $\mathrm{Q}_{\max }$ Occurs at $57.7 \%$ of the Maximum Volume Flux $\mathrm{Q}_{\max }$ under Natural Conditions

\subsubsection{Power Extraction with Momentum Sink Approach}

The hydrokinetic power extraction rate corresponding to power generation by a tidal turbine in the water body can be calculated as

$$
P=\frac{1}{2} \rho C_{T} A_{b}|\vec{u}|^{3}
$$

where $P$ is the hydrokinetic power extraction rate in $\mathrm{kg} . \mathrm{m}^{2} / \mathrm{s}^{3}$, or watts. Assuming that $N$ tidal turbines can be deployed within one model grid cell, the total energy extracted by all the turbines within that grid cell can be calculated as

$$
P_{\text {cell }}=N \times \frac{1}{2} \rho C_{T} A_{b}|\vec{u}|^{3}
$$

The tidal turbine configuration is described as follows: turbine thrust coefficient $C_{T}$ is set to 0.5 ; turbine diameter is specified as $10 \mathrm{~m}$, such that gives the flow-facing swept area $A_{b}$ of $78.54 \mathrm{~m}^{2}$. The height of the tidal turbine from the sea bed is set to $10 \mathrm{~m}$. For simplicity, the effect of the turbine structure supporting pole and foundation (the second and third terms on the right-hand side of Equation (2.2)) on the flow field is not considered. 
To properly compare the model results to the analytical solution that was derived in a 1-D domain, the model was run in a depth-averaged 2-D mode, assuming the transverse variation in the channel was small. A series of model simulations was conducted with an increasing number of tidal turbines within each grid cell. Model results indicated that the extractable power reached a maximum when the number of turbines per cell is increased to 55 and the volume flux is reduced to $58.4 \%$ of the natural volume flux (Figure 2.3), which is very close to the value of 57.7\% given by Garrett and Cummins (2005) in their analytical solution (Equation (2.11)).

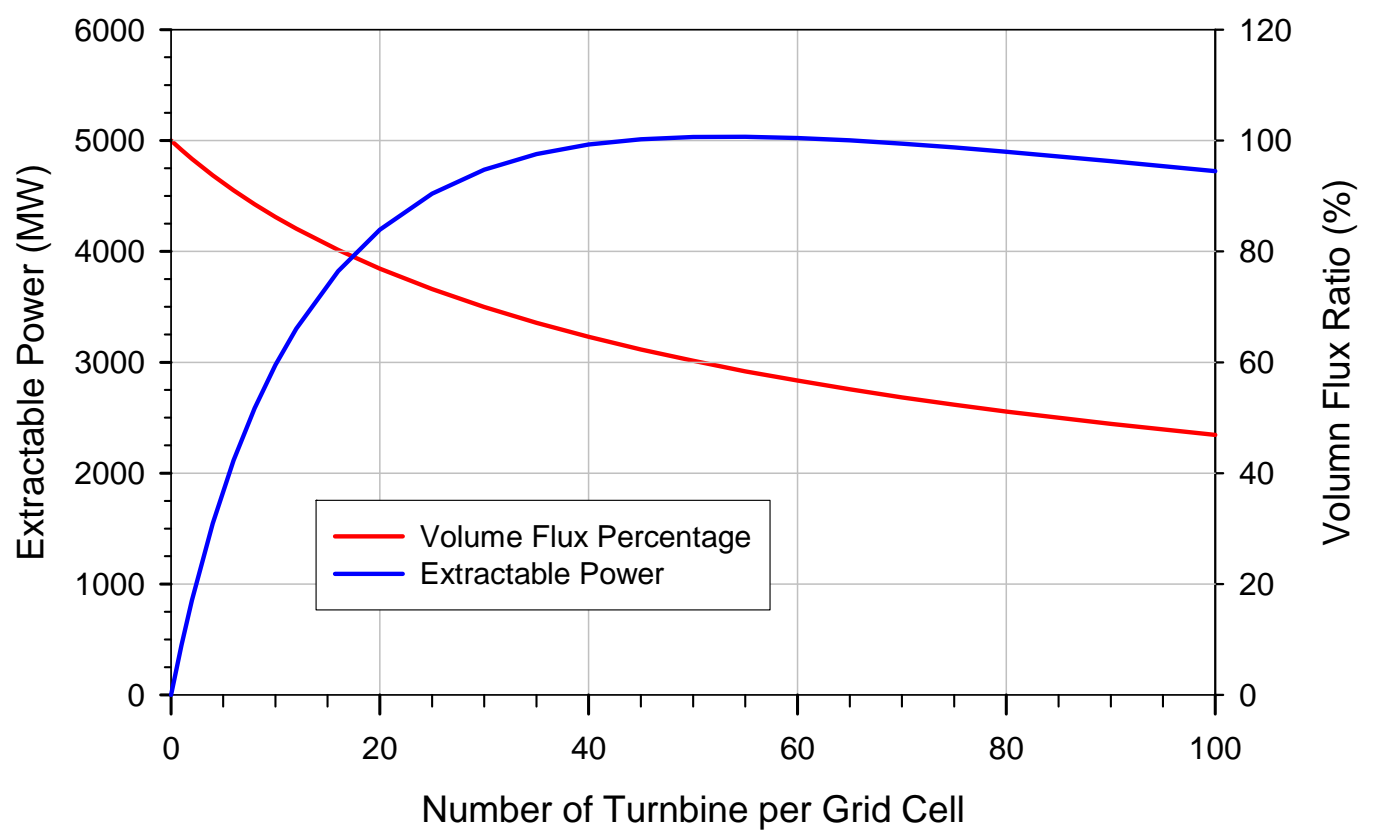

Figure 2.3. Extractable Power and Volume Flux Ratio vs. Number of Tidal Turbines in 2-D Simulation

\subsubsection{Power Extraction with Bottom Friction Approach}

To further validate the MHK scheme using the momentum sink approach described in Section 2.1.2, we repeat the same model simulations for power extraction using the bottom friction approach with the same model FVCOM in the 2-D mode. The bottom friction approach has been used in a number of studies with validation against the analytical solution (Karsten et al. 2008; Sutherland et al. 2007). The power extracted by bottom friction for a section of the seabed (with multiple model grid cells) can be calculated as (Sutherland et al. 2007)

$$
P_{\text {total }}=\iint_{A} \rho C_{d}|\vec{u}|^{3} d A
$$

where $C_{d}$ is the bottom friction coefficient (unitless) and $A$ is the model grid cell area of the seabed $\left(\mathrm{m}^{2}\right)$.

For a single model grid cell, the power extracted is calculated as

$$
P_{\text {cell }}=\rho C_{d}|\vec{u}|^{3} A_{c}
$$


where $P_{\text {cell }}$ is the power extracted by a single model grid cell. The equivalent energy extraction rates by momentum sink and the bottom friction approaches can be related by the following formula:

$$
P=\frac{1}{2} \rho C_{T} N A_{b}|\vec{u}|^{3}=\rho C_{d} A_{c}|\vec{u}|^{3}
$$

The equivalent bottom friction corresponding to the number of turbines per grid cell can be determined by

$$
C_{d}=\left(\frac{C_{T} A_{b}}{2 A_{c}}\right) N
$$

Given grid cell area $A_{c}=148,663 \mathrm{~m}^{2}$, turbine diameter $D=10 \mathrm{~m}$, and swept area $A_{b}=0.25 \pi D^{2}=78.54$ $\mathrm{m}^{2}, C_{T}=0.5$, Equation (2.10) becomes

$$
C_{d}=0.000132 N
$$

Based on Equation (2.18), we can calculate the equivalent bottom friction values corresponding to the number of turbines used in the momentum sink approach model runs described in Section 2.2.4. As indicated in Section 2.2.4, the maximum power occurs when the number of turbines per grid cell increases to 55. Therefore, the equivalent bottom friction corresponding to the maximum power would be $C_{d}=0.000132 \times 55=0.00726$.

The power extraction then can be calculated by running the FVCOM model in the 2-D mode with the new bottom friction values in the turbine grid cells. Model results using the bottom friction approach are presented in Figure 2.4. The maximum power occurs at $C_{d}=0.0072$, which is nearly identical to the value of 0.00726 estimated by Equation (2.18). Figure 2.4 also shows the maximum power occurs as volume flux reduces down to $58.8 \%$ of the natural volume flux, which is also very close to numbers obtained by the momentum sink $(58.4 \%)$ and the analytical solution $(57.7 \%)$.

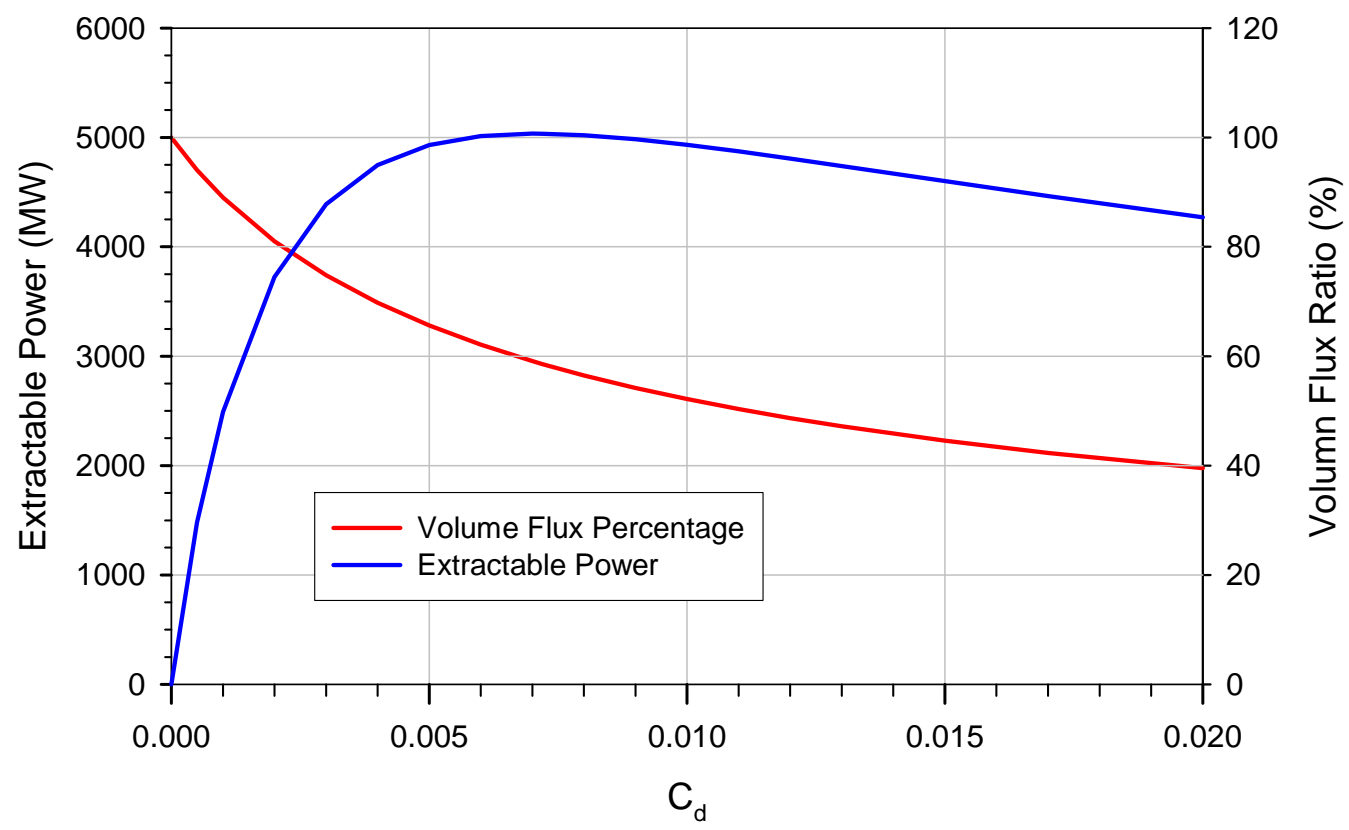

Figure 2.4. Extractable Power and Volume Flux Ratio vs. Bottom Friction in 2-D Simulations 



\subsection{Three-Dimensional Effects}

\subsection{Three-Dimensional Effect on Velocity Profile}

To be consistent with the analytical solution, all model runs described in Section 2 were conducted in a depth-averaged 2-D mode. However, in reality, tidal turbines are deployed in the water column with 3$\mathrm{D}$ variability of the flow field. To investigate the 3-D effect, model simulations in the 3-D mode were conducted for the same turbine configuration described in Section 2. In this study, 21 uniformed vertical layers in a sigma-stretched coordinate were specified in the 3-D model setup.

The velocity profiles at a center location in the tidal channel for different tidal turbine configurations show that deployment of tidal devices for energy extraction will affect the velocity profiles, especially for large-scale deployment (Figure 3.1).

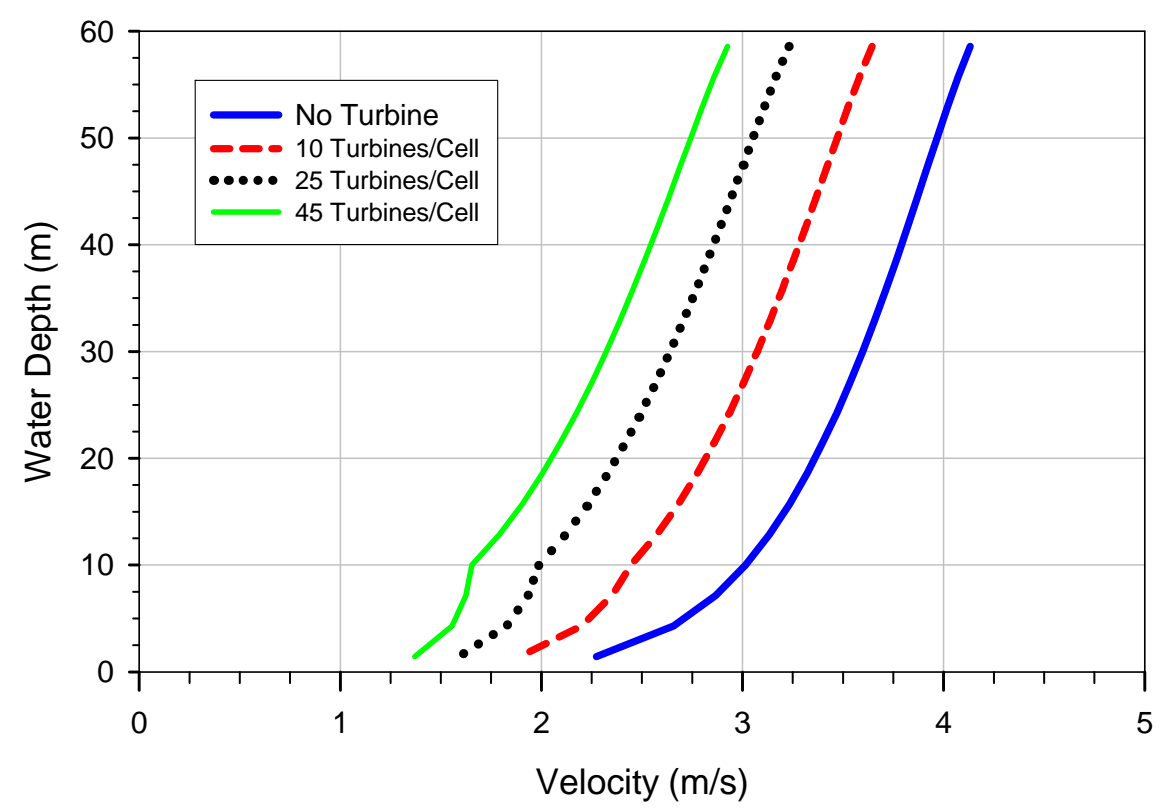

Figure 3.1. Vertical Velocity Profiles at Peak Flood Tide at the Center of the Tidal Channel for Different Numbers of Tidal Turbines (Note: the center of the turbine is $10 \mathrm{~m}$ from the seabed.)

Figure 3.2 shows maximum flood tide velocity profiles with tidal turbines located at different depths of the water column. It indicates that vertical velocity profiles vary significantly when the turbine is installed at different depths of the water column. In general, when turbines are installed closer to the seabed, it has less effect on the shape of the velocity profile and it basically behaves like an increase of the bottom friction. However, as the turbine height moves towards the middle and upper layers of the water column, both the shape and magnitude of the velocity profiles are greatly affected. 


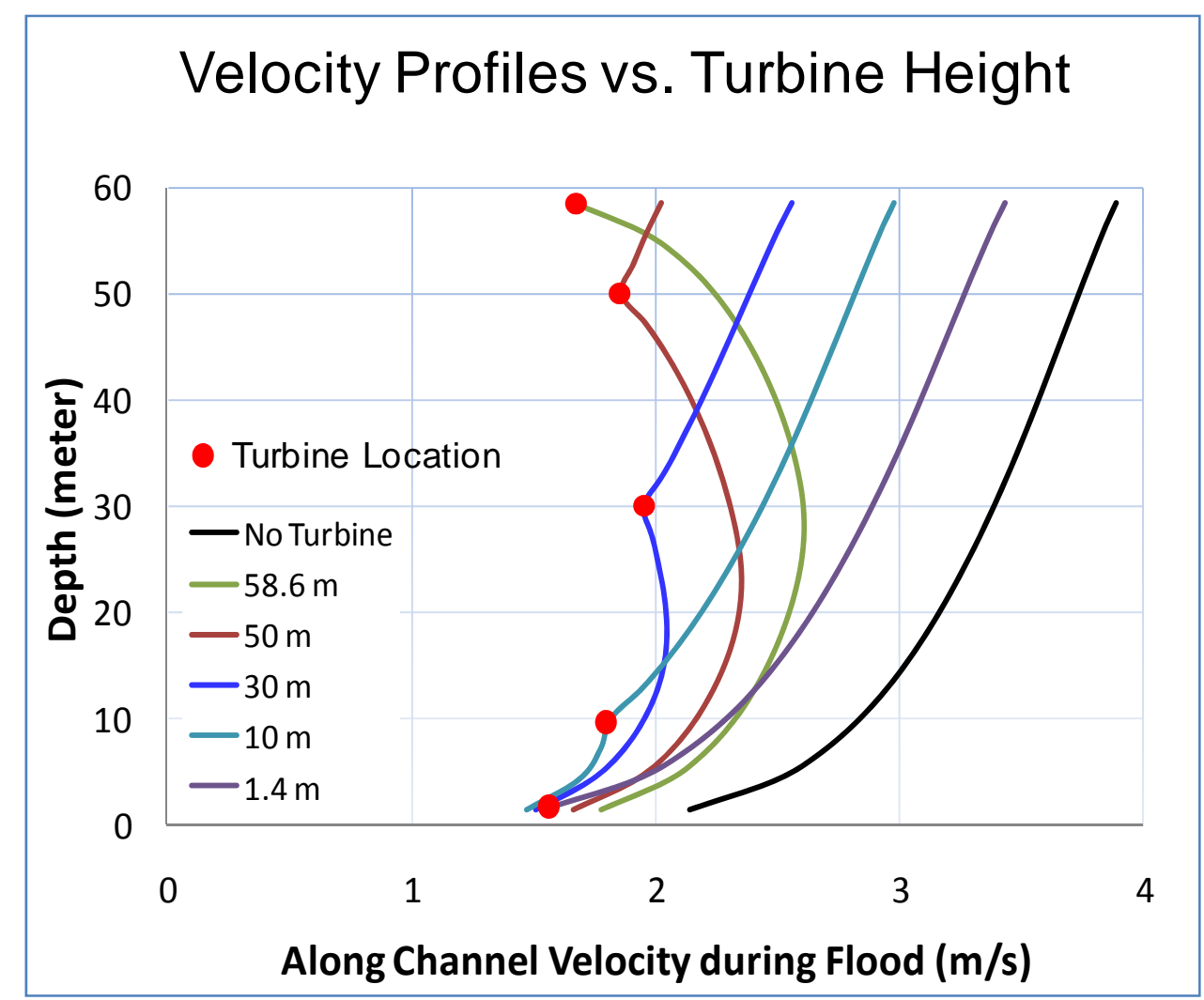

Figure 3.2. Effect of Turbine Height on Vertical Velocity Profiles at Peak Flood Tide

\subsection{3-D Effect on Maximum Extractable Energy and Volume Flux}

Model result for the 3-D model run with turbines installed at a 10-m height from the seabed shows that the extractable energy reached the maximum value when the volume flux is reduced to $67.3 \%$ of the natural condition (Figure 3.3), which is higher than the value reported by Garrett and Cummins (2005) (57.7\%) and 2-D numerical experiments reported in Section 2.2.4 (58.4\%). Additional model runs with turbines at different heights in the water column indicate that maximum power occurred when the volume fluxes were within the range of $64 \%$ to $77.0 \%$, consistently higher than the 2-D result. Figure 3.3 also shows that the maximum extractable power is smaller than that predicted under the 2-D mode (Figure 2.4). This preliminary result indicates that 1-D and 2-D approximations in assessment of potential extractable tidal energy may overestimate the effect on the reduction of volume flux and the maximum power potential. 


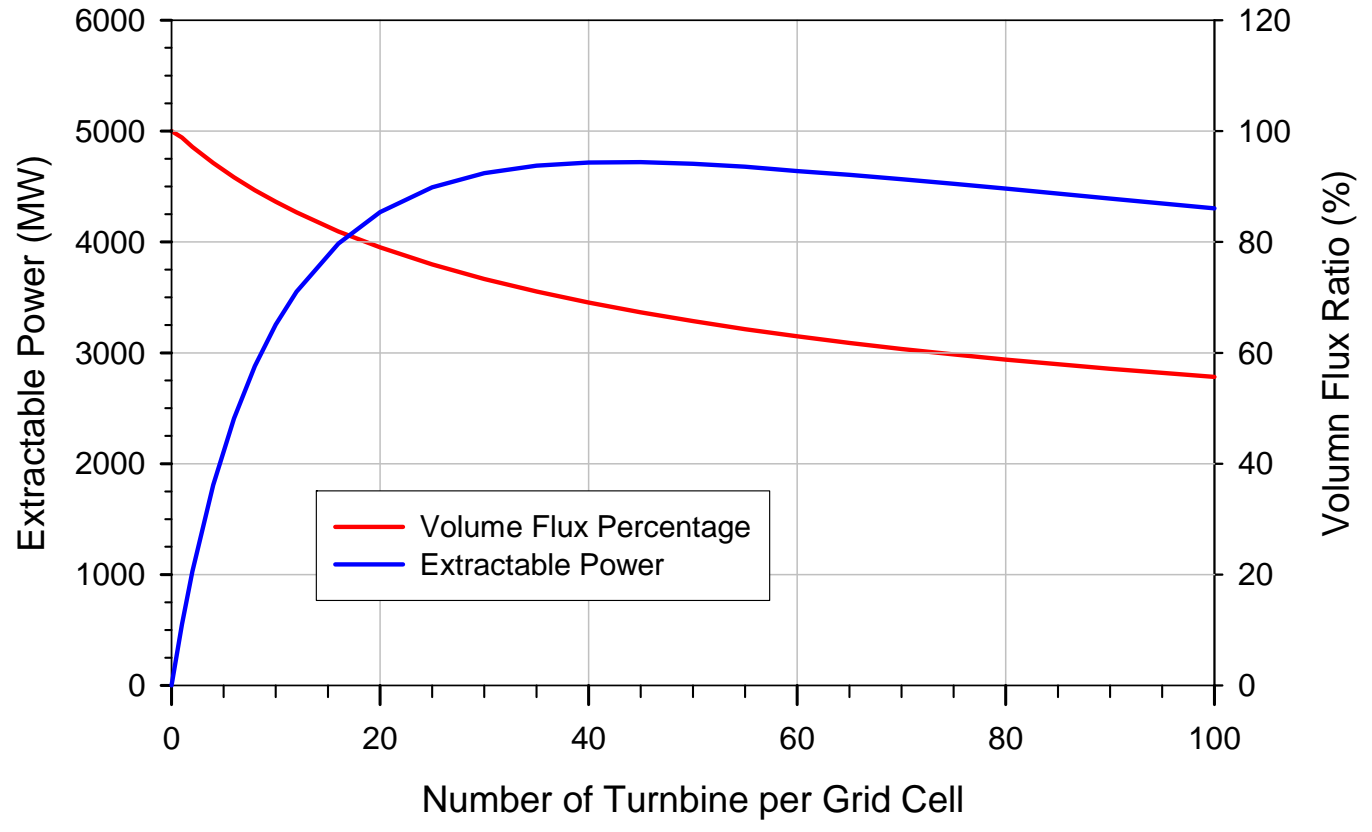

Figure 3.3. Extractable Power and Volume Flux Ratio vs. Number of Tidal Turbines in 3-D Simulation 



\subsection{Screening Analysis of MHK Array Configurations}

The model runs presented in Sections 2 and 3 are at large scale turbine deployment ( $>1000$ turbines). In reality, the number of tidal turbines deployed in a single tidal bay is generally much smaller in order to avoid any significant impact on physical processes and marine ecosystem. This section describes the application of the MHK model to cases with a much smaller number of turbines.

Before we conducted the comparative analysis of turbine configurations for the small number of turbines, we want to first demonstrate the flexibility of the unstructured grid model in simulating tidal turbines at finer grid resolution. A model simulation was thus conducted to demonstrate how the model grid can be easily refined to simulate the local effect of turbines on the flow field. In this model run, a total of 26 turbines were installed $230 \mathrm{~m}$ apart across the channel. The model grid in the region of tidal turbines was refined to a minimum cell size of $18 \mathrm{~m}$ (Figure 4.1 ). Figure 4.1 shows the velocity magnitude distribution at the turbine height $(10 \mathrm{~m})$. It can be seen that the velocity at the turbine deployment location was reduced due to the energy removal by the turbines.

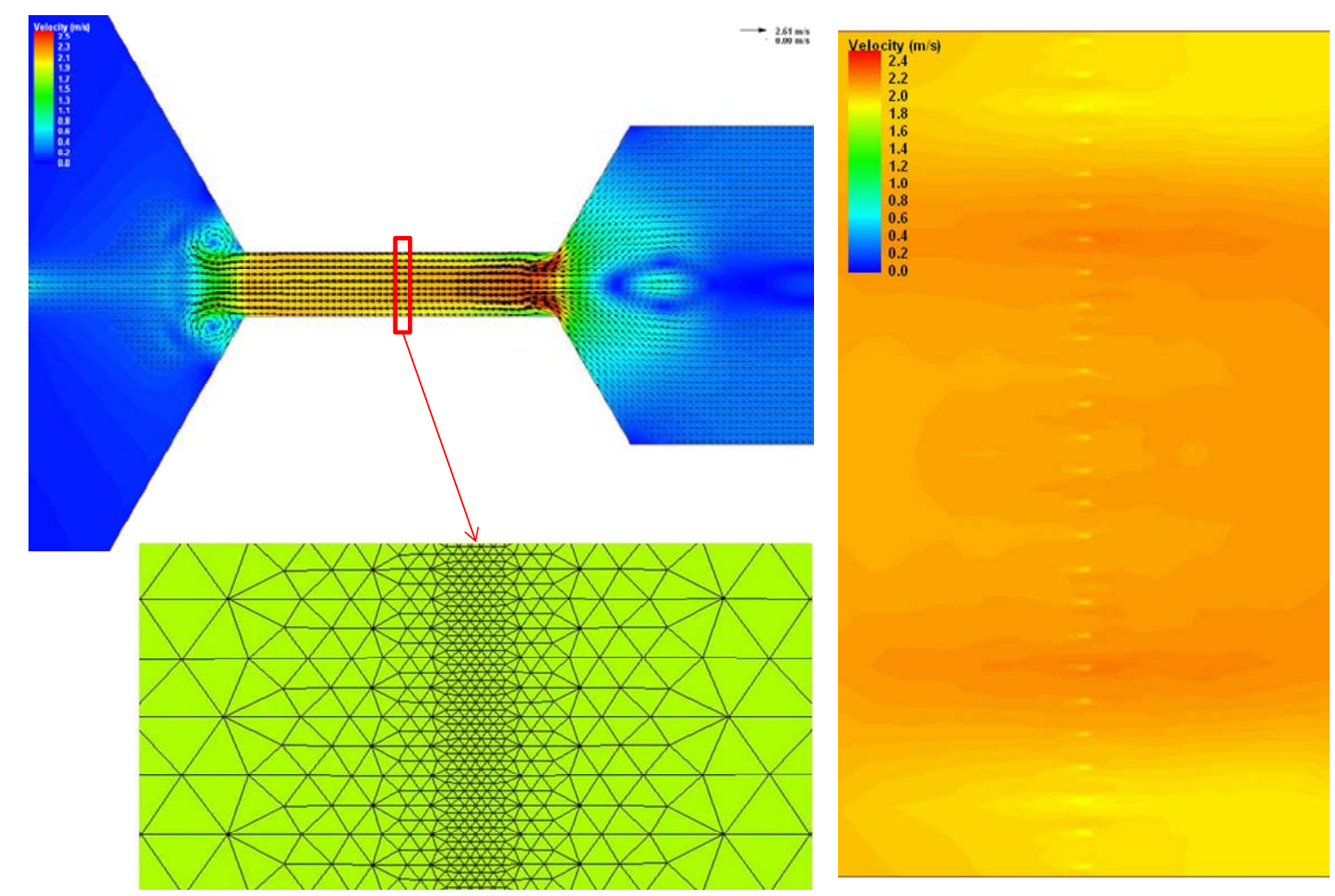

Figure 4.1. Grid Distribution Around the Tidal Turbines and Simulated Velocity Distribution

For the comparative analysis of turbine configurations with the small number of turbines, three different array configurations with a total of 102 turbines were simulated to investigate the power extraction efficiency and effects on volume flux. One of the common configurations would be deploying the turbines evenly spaced at the center of the tidal channel (Case 1). A similar configuration but with higher turbine density is also considered in the simulation (Case 2). Another configuration considered in 
the analysis is to deploy the array with the same turbine density as Case 2 but located on the side of the channel (Case 3). Figure 4.2 shows the three different configurations being modeled.

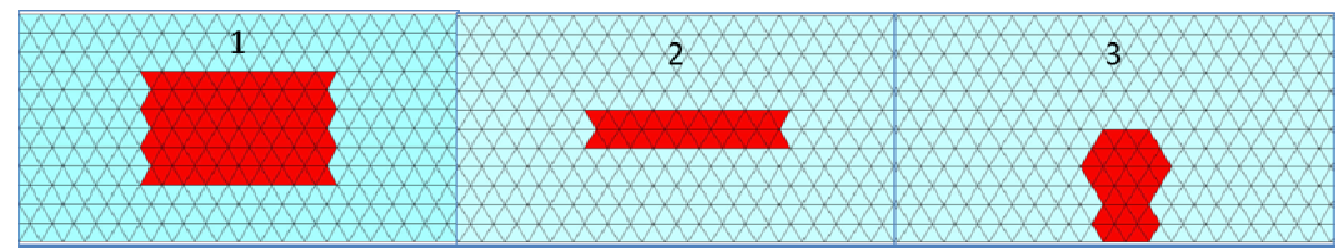

Figure 4.2. Turbine Array Configurations in the Tidal Channel

Model results indicate that the configuration with lower spatial tidal turbine density can generate more energy than a higher tidal turbine density configuration with the same number of turbines because of interaction effect between turbines. For example, Case 1 with lower spatial turbine density generates more energy than Cases 2 and 3, in which the spatial turbine densities are three time higher than those in Case 1. In addition, the amount of extracted energy also depends on the spatial distribution of velocity field where the tidal turbine array is located. For instance, in Case 2, where turbines are deployed in the center of the channel where currents are strongest, more power is generated than in Case 3, where turbines are deployed on the side of channel. Due to the small number of turbines, the effect on the reduction of volume flux is very small $(<0.2 \%)$ and basically the same for all three configurations. The model runs with different turbine configurations are listed in Table 4.1.

Table 4.1. Array Configurations

\begin{tabular}{ccccc}
\hline Case & $\begin{array}{c}\text { Number of Cells } \\
\text { with Turbines }\end{array}$ & $\begin{array}{c}\text { Number of } \\
\text { Turbines per Cell }\end{array}$ & Configuration & $\begin{array}{c}\text { Extracted } \\
\text { Energy (MW) }\end{array}$ \\
\hline 1 & 102 & 1 & Center & 55.9 \\
2 & 34 & 3 & Center & 49.4 \\
3 & 34 & 3 & Side & 48.5 \\
\hline
\end{tabular}




\subsection{MHK Effects on Hydrodynamics and Flushing Time}

It is useful to use numerical models to investigate the power extraction efficiency and effects on physical processes such as tidal elevation, velocity field and flushing time of the bay.

To further examine the effect of tidal turbines on the tidal amplitudes and currents inside the bay, the spatial distributions of M2 tidal amplitude and currents for conditions without turbine deployment and with 10 turbines per cell are compared in Figures 5.1 and 5.2, respectively. Simulating the natural conditions (without turbine) shows a significant increase of tidal amplitudes inside the bay compared to open boundary and strong tidal currents in the narrow tidal channel. One can also see that the presence of tidal turbines in the channel substantially changed the tidal dynamics in the system. The tidal amplitude inside the bay was much reduced compared with the natural condition. For instance, in the middle portion of the bay, tidal amplitude was reduced from $1.97 \mathrm{~m}$ for the natural condition to $1.72 \mathrm{~m}$ for the turbine case. The decreased tidal amplitude will reduce the tidal flow into and out of the bay. As seen from Figure 5.1, the maximum change in tidal amplitude occurred at the end of the bay.

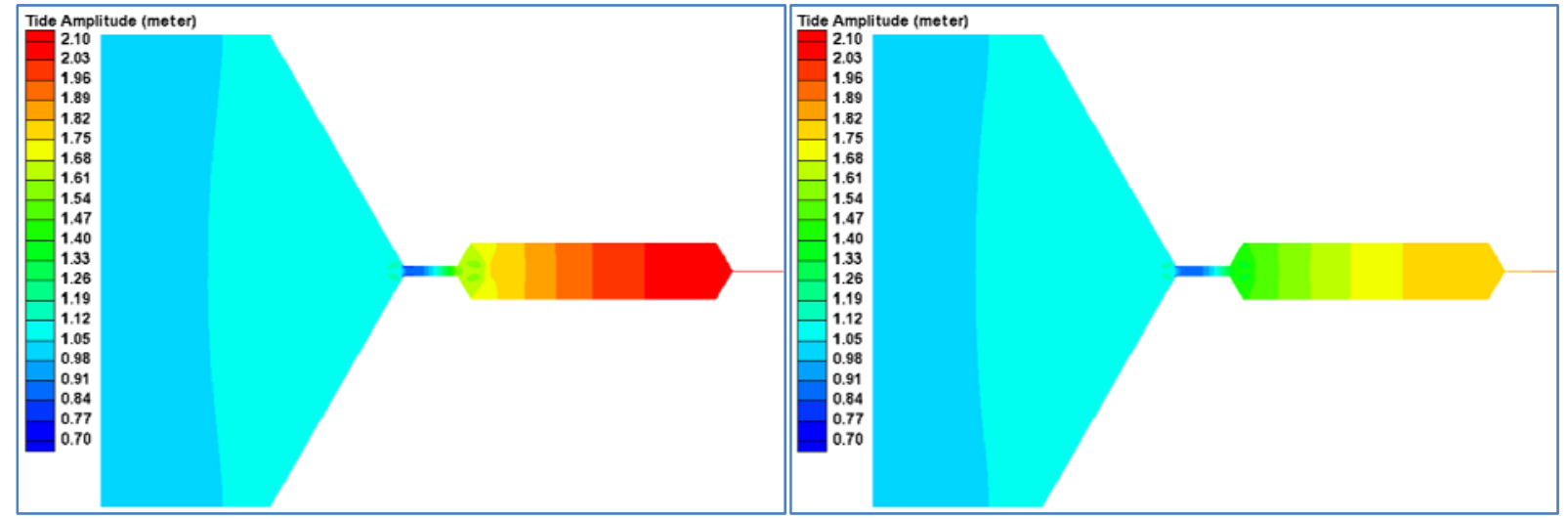

Figure 5.1. Simulated Tidal Amplitudes Without (Left) and With 10 Tidal Turbines per Cell (Right)

Similarly, comparisons of tidal currents at flood and ebb tides with and without tidal turbines show that the deployment of tidal turbines also reduced the tidal currents in the tidal channel. Maximum tidal currents in the channel could be as high as $4.3 \mathrm{~m} / \mathrm{s}$ under natural conditions. However, with the presence of turbines (with 10 turbines per cell), maximum currents were reduced to $3.8 \mathrm{~m} / \mathrm{s}$. Differing from changes in tidal amplitude, the maximum change in tidal currents occurred in the narrow channel although the changes in the bay were relatively small, due primarily to the large cross-sectional area and low current speeds in the bay.

Because of the reduction of volume flux across the tidal channel due to deployment of tidal turbines, one can expect that the flushing rate of the bay will be reduced with the presence of tidal turbines. To further examine the negative impact of tidal turbines on the flushing rate, numerical experiments were conducted by releasing a neutrally buoyant conservative tracer (dye) in the tidal bay under the natural and turbine deployment cases. For both cases, the model was allowed to spin up for several days. After the spin-up period, the tracer with an arbitrary concentration of $1 \mathrm{mg} / \mathrm{L}$ was instantaneously released at all the nodes within the bay at the slack before ebb tide. At the open boundary, in-coming tracer concentration was prescribed as zero. Figure 5.3 shows a snapshot of tracer concentrations in the model domain, at the 
20th day after the initial release under the natural conditions and with tidal turbines in place (10 turbines per grid cell). Clearly, compared with the natural conditions, much more tracer was retained inside the bay after 20 days of initial release. By further assuming the tracer mass decreases exponentially inside the bay, the estimated flushing times (e-folding time) of the bay are 45.4 days and 75.9 days, respectively, for the natural and turbine deployment cases. While the volume flux with the 10 turbines per cell configuration was reduced to about $87 \%$ of the natural condition (or $13 \%$ reduction), the flushing time was increased by $67 \%$ when tidal turbines were deployed.
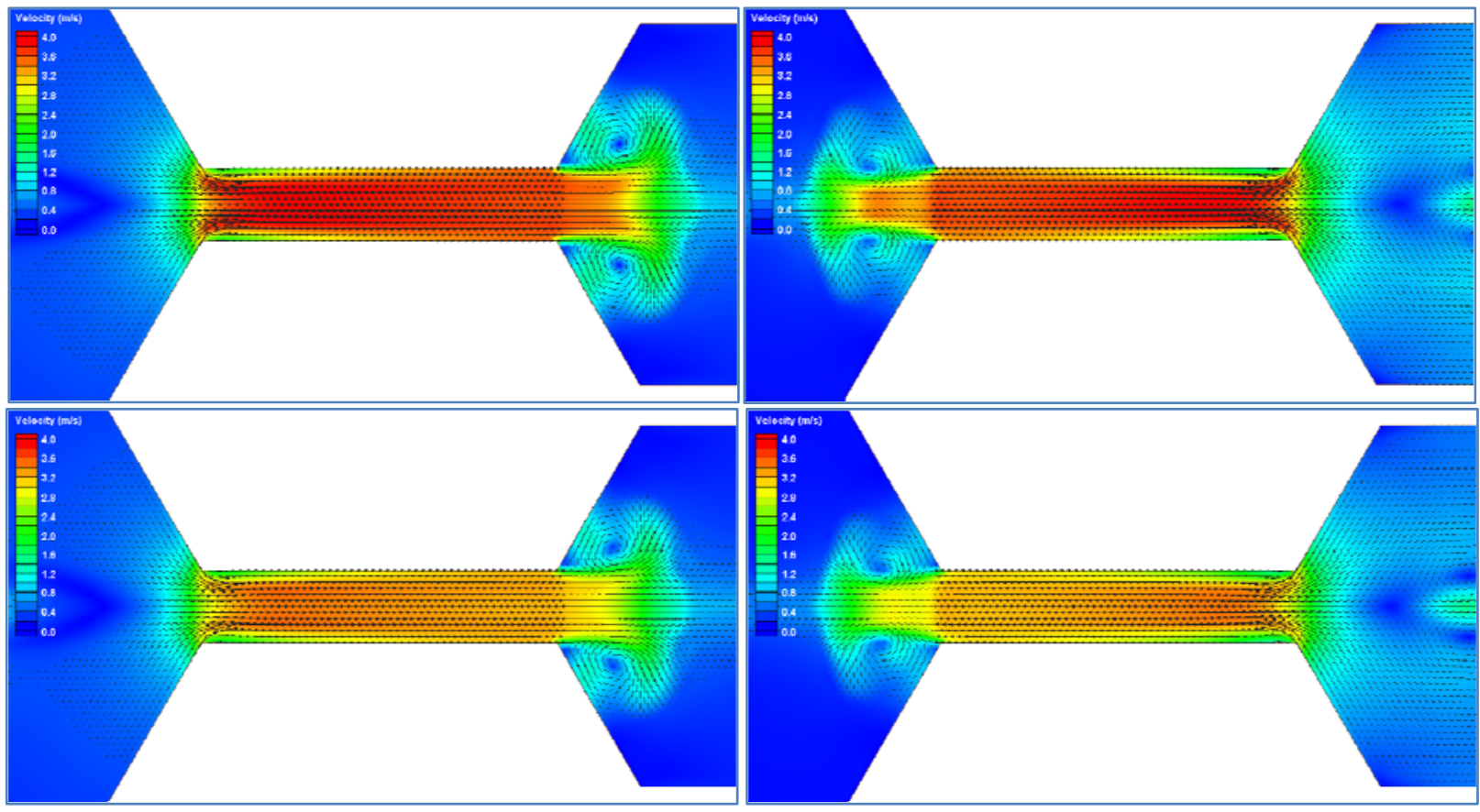

Figure 5.2. Simulated Surface Tidal Currents at Flood and Ebb Tides Without (upper - left and right) and With 10 Tidal Turbines per Cell (bottom - left and right)

Reduced flushing rate of a tidal embayment has been shown to be positively correlated with increased incidences of low dissolved oxygen, eutrophication, impacts on higher levels of the marine food web, and failures of fisheries (Frankignoulle et al. 1998; Diaz 2001; Chan et al. 2008).

To investigate how flushing time of the bay changes as a function of the number of tidal turbines deployed in the channel, a series of model runs was conducted with different numbers of tidal turbines. 

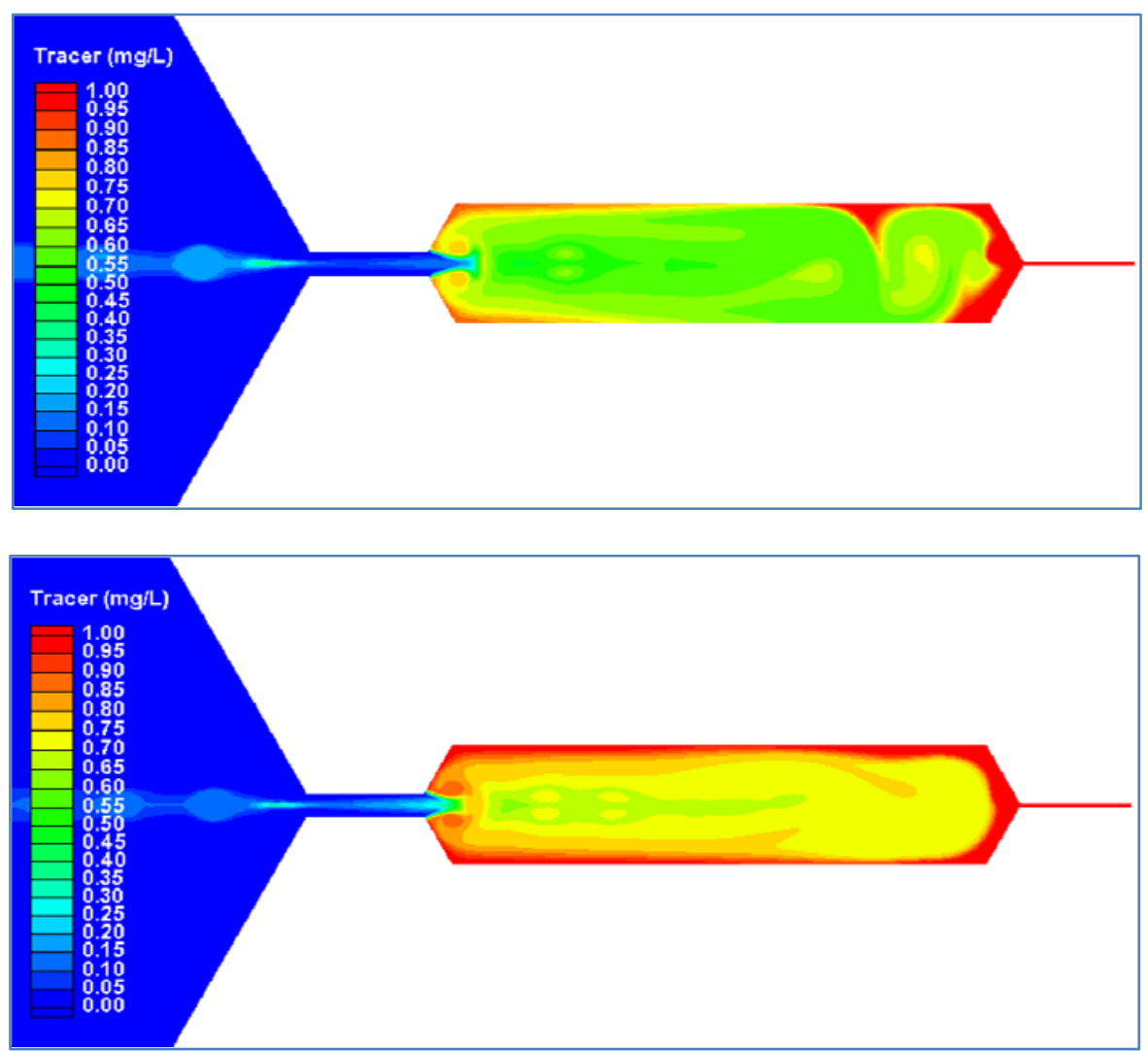

Figure 5.3. Simulated Tracer Concentrations Without (top) and With Tidal Turbines (bottom 10 turbines per cell) at 20th day after Initial Release

Figure 5.4 shows that as the number of tidal turbines in the channel increases, not only the flushing time in the bay increases but also the gradient, which indicates the flushing time increases faster at the higher number of turbines. To further analyze this, we looked at the percentage increment of flushing time as a function of relative volume flow reduction (Figure 5.5). One can see the relative increase of the flushing time as it increases nearly exponentially as the percentage of the volume flux reduction increases. Therefore, increase of tidal turbines has a stronger effect on relative change of flushing time than the percentage reduction in volume flux. 


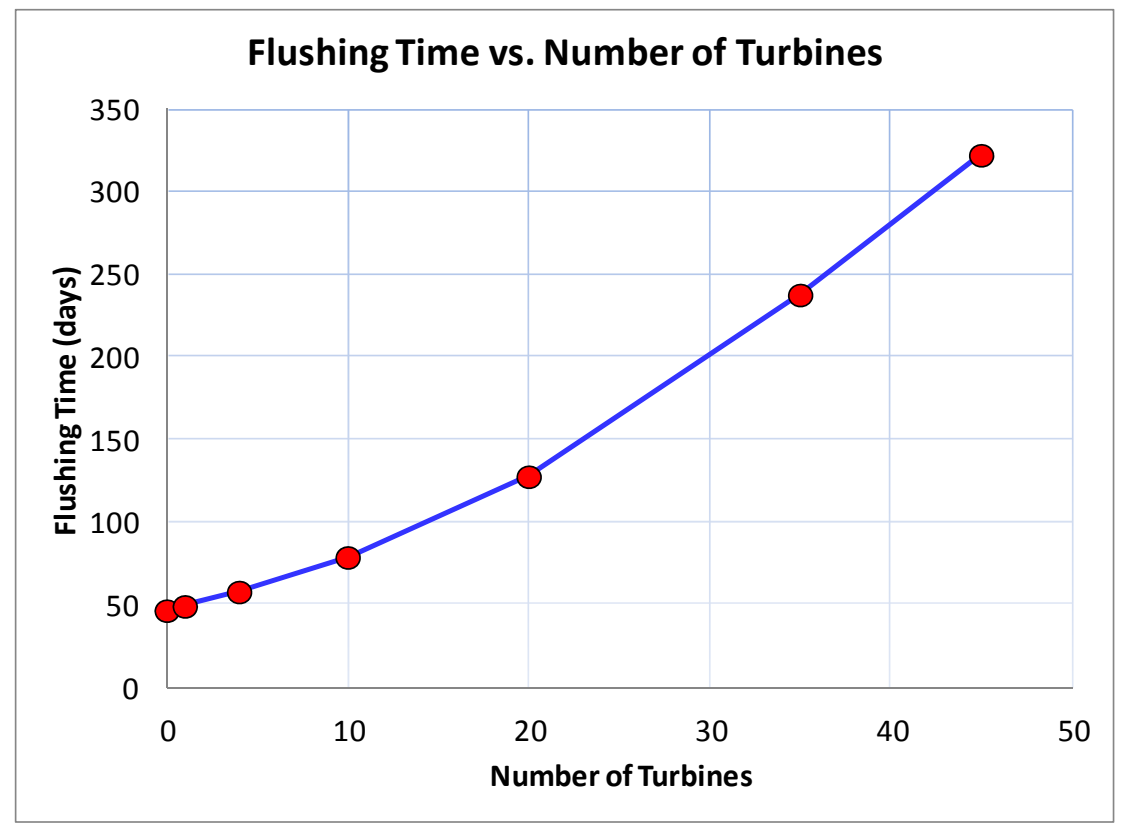

Figure 5.4. Effect of the Number of Turbines on the Flushing Time

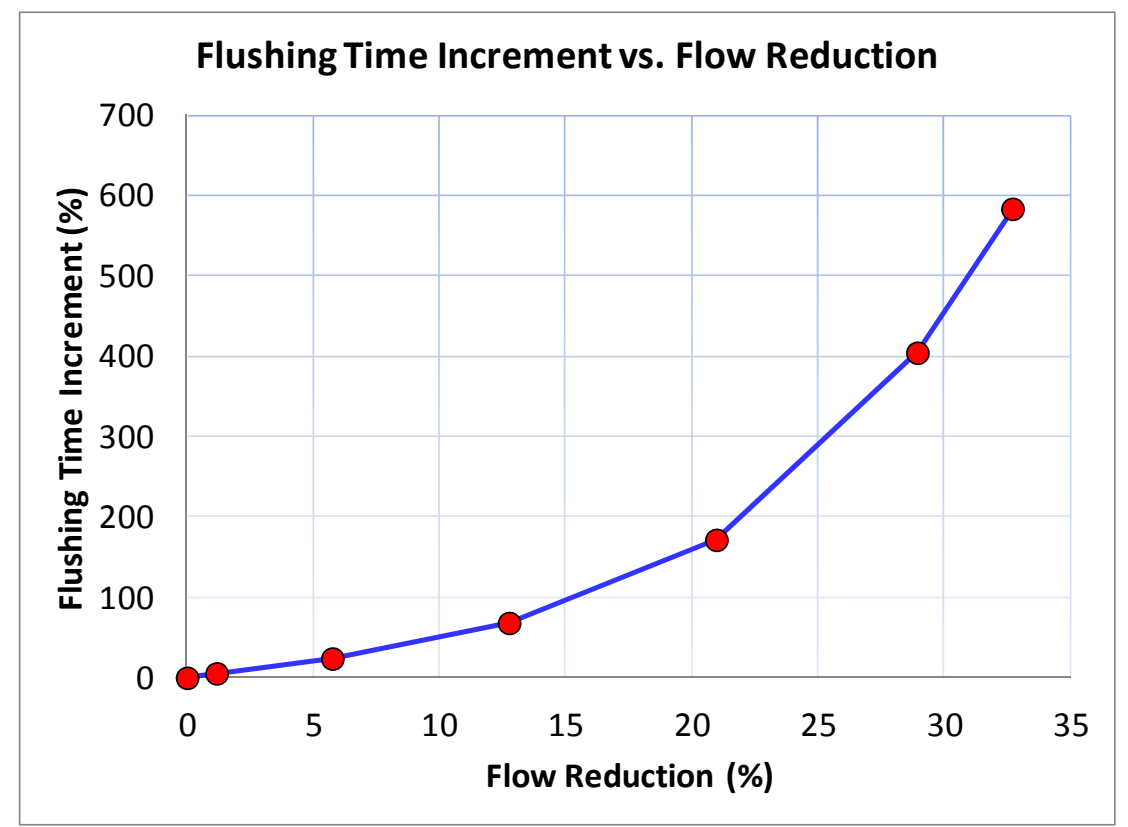

Figure 5.5. Flushing Time Increment vs. Flow Reduction 


\subsection{Summary}

In this study, an MHK module was incorporated into a 3-D coastal ocean model FVCOM using the momentum sink approach. A series of numerical experiments were carried out to simulate the effect of tidal energy extraction on the volume flux and tidal dynamics in an idealized tidal bay, which is connected to the coastal ocean through a narrow tidal channel. Model results in the depth-averaged 2-D mode showed good agreement with the 1-D analytical solution, which was derived using the quadratic friction approach (Garrett and Cummins 2005). The momentum sink approach was also validated against the bottom friction approach in the depth-averaged 2-D mode. The good agreement indicates that the MHK module incorporated in FVCOM with a momentum sink approach can be used to assess the effects of tidal energy removal on the physical prcoesses and ecosystem.

Sensitivity model runs were conducted to investigate the 3-D effects of MHK devices on the velocity profiles and energy extraction. While model results in a depth-averaged model matched the analytical solution well, 3-D simulations for the same tidal turbine configurations indicated that the volume flux reduction at the maximum power extraction is in a much lower range of 23 to $36 \%$ of the natural condition, which is smaller than the value of $42 \%$ from the 1-D analytical solution and depth-averaged 2$\mathrm{D}$ model results. This is because tidal flows can bypass tidal turbines in either the lower or upper water columns when tidal turbines are simulated in a 3-D mode.

Preliminary model results also show that MHK devices have greater effect on the relative change in flushing time than the change in volume flux.

Finally, although the MHK module was developed in a coastal ocean model and validated in an idealized tidal system, it can be also applied to river and ocean current energy extraction for assessment of physical and environmental effects. 



\subsection{References}

Atwater J and G Lawrence. 2010. "Power potential of a split channel.” Renewable Energy 35:329-332.

Chan F, J Barth, J Lubchenco, A Kirincich, H Weeks, W Peterson, and B Menge. 2008. "Emergence of Anoxia in the California Current Large Marine Ecosystem." Science 319:920.

Chen C, H Liu, and RC Beardsley. 2003. "An unstructured, finite-volume, three-dimensional, primitive equation ocean model: application to coastal ocean and estuaries." Journal of Atmospheric and Oceanic Technology 20:159-186.

Chen, C., G. Cowles, and RC Beardsley. 2006. "An unstructured grid, finite volume coastal ocean model: FVCOM User Manual, Second Edition". SMAST/UMASSD Technical Report-06-0602, pp. 315.

Chen C, G Gao, J Qi, A Proshutinsky, RC Beardsley, Z Kowalik, H Lin, and G Cowles. 2009. “A new high-resolution unstructured-grid finite-volume Arctic Ocean model (AO-FVCOM): an application for tidal studies." Journal of Geophysical Research, doi:10.1029/2008jc004941.

Diaz RJ. 2001. “Overview of Hypoxia around the World.” Journal of Environmental Quality 30:275-281.

Draper S, GT Houlsby, MLG Oldfield, and AGL Borthwick. 2009. Modelling tidal energy extraction in a depth-averaged coastal plain." Proceedings of the $8^{\text {th }}$ European Wave and Tidal Energy Conference, Uppsala, Sweden.

Frankignoulle M, GL Abril, A Borges, I Bourge, C Canon, B Delille, E Libert, and J-M Theate. 1998. "Carbon Dioxide Emission from European Estuaries." Science 282:434-436.

Garrett C and P Cummins. 2005. "The power potential of tidal currents in channels." Proceedings of The Royal Society A 461:2563-2572.

Garrett C and P Cummins. 2007. "The efficiency of a turbine in a tidal channel." The Journal of Fluid Mechanics 588:243-251.

Hu S, DW Townsend, C Chen, G Cowles, RC Beardsley, R Ji, and RW Hounghton. 2008. "Tidal pumping and nutrient fluxes on Georges Bank: a process-oriented modeling study." Journal of Marine Systems 74:528-544, doi:10.1016/j.jmarsys.2008.04.007.

Huang H, C Chen, JO Blanton, and FA Andreade. 2008. "A numerical study of tidal asymmetry in Okatee Creek, South Carolina.” Coastal and Shelf Science 78(1):190-202.

Karsten, RH, JM McMillan, MJ Lickley, and RD Haynes. 2008. "Assessment of Tidal Current Energy in the Minas Passage, Bay of Fundy" Proceedings of the Institution of Mechanical Engineers, Part A:

Journal of Power and Energy 222: 493-507. 
Lai Z, C Chen, G Cowles, and RC Beardsley. 2010. "A Non-Hydrostatic Version of FVCOM, Part II: Mechanistic Study of Tidally Generated Nonlinear Internal Waves in Massachusetts Bay." Journal of Geophysical Research-Oceans, doi: 10.1029/2010JC006331.

Parker DM. 1993. "Environmental implications of tidal power generation." IEE Proceedings $A$ 140(1):71-75.

Pelc R and RM Fujita. 2002. "Renewable energy from the ocean.” Marine Policy 26:471-479.

Polagye BL and PC Malte. 2011. "Far-field dynamics of tidal energy extraction in channel networks." Renewable Energy 36(1):222-234.

Polagye B, B Van Cleve, A Copping, and K Kirkendall (eds.). 2011. Environmental Effects of Tidal Energy Development. NOAA Technical Memo, F/SPO-116, U.S. Department of Commerce, Washington, D.C.

Shapiro G. 2010. "Effect of tidal stream power generation on the region-wide circulation in a shallow sea." Ocean Science Discussions 7:1785-1810.

Sun X, JP Chick, and IG Bryden. 2008. "Laboratory-scale simulation of energy extraction from tidal currents." Renewable Energy 33:1267-1274.

Sutherland G, M Foreman, and C Garrett. 2007. "Tidal current energy assessment for Johnstone Strait, Vancouver Island." Proceedings of the IMechE, Part A: Journal of Power and Energy 221(A2):147e57.

Walkington I and R Burrows. 2009. "Modelling tidal stream power potential." Applied Ocean Research 31:239-245.

Weisberg, RH and L Zheng. 2006. "Circulation of Tampa Bay driven by buoyancy, tides, and winds, as simulated using a finite volume coastal ocean model." Journal of Geophysical Research doi:10.1029/2005JC003067.

Xing J, AM Davies, and JE Jones. 2011. "Application of an unstructured mesh model to the determination of the baroclinic circulation of the Irish Sea." Journal of Geophysical Research, doi:10.1029/2011JC007063.

Yang Z and T Khangaonkar. 2010. "Multi-scale Modeling of Puget Sound Using an Unstructured-grid Coastal Ocean Model: From Tide flats to Estuaries and Coastal Waters." Journal of Ocean Dynamics 60:1621-1637, doi:10.1007/s10236-010-0348-5.

Yang Z, T Wang, T Khangaonkar, and S Breithaupt. 2011. "Integrated modeling of flood flows and tidal hydrodynamics over a coastal floodplain." Environmental Fluid Mechanics, doi:10.1007/s10652 011-9214-3.

Zhao L, C Chen, and G Cowles. 2006. "Tidal flushing and eddy formation in Mount Hope Bay and Narragansett Bay: an application of FVCOM." Journal of Geophysical Research, 111:C10015, doi:10.1029/2005JC003135. 
Zheng, L, C Chen, and H Liu. 2003. "A 3-D modeling study of the Satilla River estuarine System. Part I: simulation of flooding/drying processes." Estuaries, 26:651-669. 


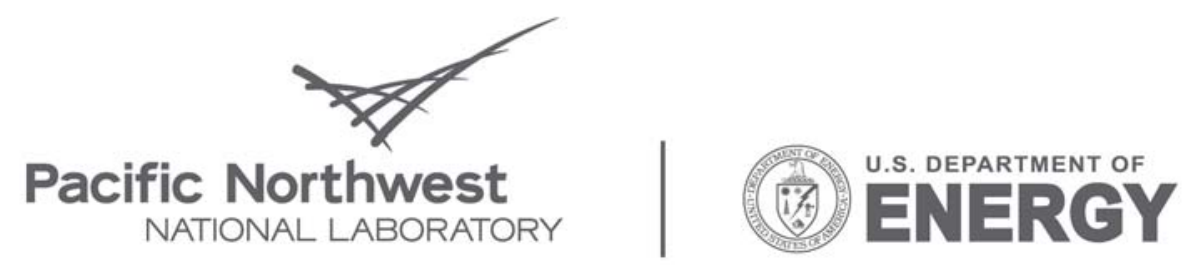

Proudly Operated by Battelle Since 1965

902 Battelle Boulevard

P.O. Box 999

Richland, WA 99352

1-888-375-PNNL (7665)

www.pnl.gov 